\title{
Upper respiratory tract infection in children, domestic temperatures, and humidity
}

\author{
Alistair Ross, Mike Collins, Christopher Sanders
}

\begin{abstract}
Study objective-The aim of the study was to seek for a possible association between the incidence of upper respiratory tract infections and air temperature and humidity in the home.

Design-Recordings of temperature and relative humidity were made in living rooms and children's bedrooms over a six month period and related to incidence of upper respiratory tract infection.

Setting-The study was carried out in one general practice of 10000 patients.

Patients-297 children aged 24-59 months were studied, selected in random order from the practice age-sex register.

Measurements and main resultsTemperature and humidity recordings were made with thermohygrograph recorders over six days. Upper respiratory tract infections were recorded (a) retrospectively over the previous 12 months, and (b) during the study period. Past history of actute otitis media and recent family history of respiratory infection were also obtained. No significant association was found between the variables, although the bedrooms of children with reported upper respiratory tract infections were cooler overnight than those of non-infected children (mean difference $0.8^{\circ} \mathrm{C}, 95 \%$ confidence limits $0.7^{\circ} \mathrm{C}$ ). No association was found between reported or recorded upper respiratory tract infections and age or type of home, family size, level of occupancy, social class, or smoking habits. Only 15 children $(5 \%)$ were identified by their parents as having had asthma, but $58(19.5 \%)$ had had a "wheezy chest". A greater proportion of children who wheezed slept in cooler bedrooms, had gas fires rather than central heating, and had more smokers in the house.

Conclusions-No association between upper respiratory tract infection and domestic temperature or humidity levels could be shown in this study. Since dampness is repeatedly presented as a health risk, further study is required.
\end{abstract}

Upper respiratory tract infections are the most common group of illnesses in young children. In the preschool child the recorded incidence approximates one medical consultation per annum, ${ }^{1}$ although obviously many other episodes are treated without medical referral, and their frequency has been shown to be related to seasonal factors, family size, age and school attendances. $^{2}$ Field studies of the effects of humidity on respiratory disease have taken place in kindergarten, schools, barracks and offices, and some reports have suggested that higher humidity was associated with lower absenteeism or the occurrence of upper respiratory tract infection but the findings have not always been consistent. ${ }^{3}$ There have been fewer studies of the physical properties of domestic indoor air, but the common cold and respiratory illness have been associated with relative humidity or damp housing conditions. ${ }^{45}$ It is obvious that in this area of study environmental and behavioural factors are strongly interrelated, and in field studies variables are difficult if not impossible to isolate, therefore results must be regarded as suggestive rather than conclusive.

There are also differences of view on whether, and how, relative humidity affects respiratory illness. ${ }^{67}$ A World Health Organization report ${ }^{8}$ stated that the evidence suggests that high humidity favours the growth of moulds and bacteria, and increases the incidence of house mites and the survival of air borne pathogens; but it points out that low humidity tends to increase atmospheric dust, dry mucous membranes, and aggravate the irritation caused by tobacco smoke.

Condensation and the resulting mould growth are widespread in British housing, especially in the rented sector; at least two million houses are affected overall. ${ }^{9}$ While it is well understood that relative humidity levels above $70 \%$ promote mould growth, there is little information available on the possible risks to health of high humidities. In local authority housing, dampness is a major source of complaints and can often be a focus for more general discontent about conditions. Objective data on both health and housing are important in this sensitive field, where there is a danger in assuming that health problems are a priori an index of poor housing.

Our objective was to obtain measurements of domestic temperature and humidity from as large a sample of children in the chosen age groups as possible and to seek an association with those measurements of upper respiratory tract infection that were available and feasible.

\section{Methods}

The practice diagnostic register showed that the highest reported occurrence of acute otitis media was in children in their 3rd to 5 th years, of whom there were 354 in our practice at the beginning of the study. This age group was therefore chosen as our study group on the reasoning that the incidence of all forms of upper respiratory tract 
infection would also be high in these children. The study period was from December 1984 to May 1985 inclusive. Before the project began a letter was sent to the parents of the study children explaining the aims of the study and inviting their cooperation.

A diagnosis of upper respiratory tract infection was accepted where the parent reported or the file recorded an episode of one or more of the following: cold; coryza; cough; sore throat; tonsillitis; pharyngitis; acute otitis media; tracheitis. A recorded episode of acute otitis media was accepted from the findings of entries such as AOM (acute otitis media), OM (otitis media), ASOM (acute suppurative otitis media), inflamed TM (tympanic membrane). The entries recorded as positive were invariably associated with the prescribing of an antibiotic.

Forty thermohygrographs were borrowed from the Building Research Establishment Scottish Laboratory, East Kilbride. These instruments record temperature from a bimetallic strip, and relative humidity from the extension of a hair, on a chart mounted on a drum which rotates over seven days. ${ }^{10}$ When calibrated regularly with an aspirated psychrometer, ${ }^{11}$ temperatures are accurate to within $\pm 0.5^{\circ} \mathrm{C}$ and relative humidities to within $\pm 2^{\circ}$.

Starting in December 1984, two instruments were installed in four houses each day, Monday to Friday, and collected one week later, by one of two research assistants. The order of visits was randomly chosen from the age-sex register by computer. The machines were placed in the living room and child's bedroom approximately one metre from the floor in a position to sample average room conditions, avoiding as much as possible direct sun, draughts or other influences. The calibration of each machine was checked with an aspirated psychrometer at the start of the study and at the end of each home measurement, and corrections made where necessary. A continuous record of temperature and relative humidity over six full days was thus obtained from each room.

During May and June repeat visits were made to 58 homes selected at random, to compare internal conditions in a different season, and to enable us to confirm the reliability of the questionnaire.

The completed charts were sent in monthly batches to the Building Research Establishment where they were digitised with a graphics tablet and microcomputer. Standard equations ${ }^{11}$ were used to calculate hourly values of temperature and vapour pressure for subsequent analysis.

A questionnaire (28 questions), adapted from that used by Melia, ${ }^{5}$ was completed by the research assistant at interview with the parent or guardian when the thermohygrograph was being either installed or collected. The questionnaire obtained information on the age and type of house and period of stay there; the forms of cooking and heating used in the home; methods of ventilation used; room occupation, sleeping habits and conditions; and other social factors including smoking habits of the occupants, employment state and social class.

Outside temperatures and relative humidities were recorded using thermohygrographs in a supplementary meteorological station approx- imately 300 metres from the practice surgery. These were calibrated with readings from an official Class 2 Meteorological station at the University of Keele, some five kilometres distant.

Besides heating and other occupancy factors, the environmental conditions within houses depend on the outside climate. To allow comparison of conditions within houses visited at different stages of the winter, regression equations were calculated between the inside and outside temperatures and vapour pressure. ${ }^{12}$ These were used to correct the inside conditions to the mean outside conditions for the winter.

Four elements of clinical information were collected:

(1) At the first home visit, when the thermohygrographs were installed, the parent or guardian was interviewed, and a short questionnaire was completed by the interviewer, providing information on any upper respiratory tract infection occurring in any members of the family during the preceding week. (Specific questions were asked about the occurrence of a cold, flu, sore throat or tonsillitis, ear ache or ear discharge, pharyngitis, croup, sinusitis and tracheitis.) A second identical questionnaire was completed one week later when the machine was collected, giving us reported information for a two week period, one week before and one week during recording. To distinguish this information from that obtained from the medical records, these data are categorised as "Reported URTI".

(2) Information was also collected during the visit on whether, in the previous 12 months, the study child had a "usual cough", had been wheezy or had had an attack of asthma or bronchitis ("Reported respiratory symptoms").

(3) The number of times each child had been seen or treated by a doctor for upper respiratory tract infection during the study period ("Recorded URTI") was obtained by a search of the medical records.

(4) The number of times the child was reported to have had acute otitis media since birth ("Recorded AOM") was also obtained from the records.

Statistical analysis was performed to investigate any relationships between the clinical and environmental data. Analyses were by the appropriate independent $t$ or $\chi^{2}$ test, and Kappa statistics ${ }^{13}$ were used for assessing concordance.

\section{Results}

From the 354 children on the practice list at the beginning of the study, 14 families refused to take part, and 43 children had either moved away or could not be contacted or visited during the hours available to us. The remaining 297 were randomly visited over the study period ( 157 females and 140 males) with a mean age of 4 (SD 0.9) years.

SOCIODEMOGRAPH CHARACTERISTICS

Two hundred and two children $\left(66^{\prime \prime}\right.$ ") lived in semi-detached houses, $79\left(26 \cdot 6^{\circ}{ }_{10}\right)$ in terraced 
houses, and $15(5.1 \%)$ in detached houses. Twenty-six per cent of the houses were built pre- $1914,53 \%$ between the wars and $20 \%$ post1945. Two hundred and seventeen families $(73.1 \%)$ cooked with gas; $214(72.1 \%)$ had central heating; and $66(22.2 \%)$ mainly used gas fires for heating; 204 children $(68.7 \%)$ had a central heating radiator in their bedroom, while 59 $(19.9 \%)$ had no bedroom heating. One hundred and forty children $(47 \cdot 1 \%)$ had their own bedroom, $135(45 \cdot 5 \%)$ shared with one sibling, 21 $(7 \cdot 1 \%)$ with two and one $(0.3 \%)$ with three. Sixteen $(5.4 \%)$ had only one parent living with them in the home. Of the remaining 281 children $18(6.1 \%)$ had three adults in the house, three $(1.0 \%)$ had four, and two $(0.6 \%)$ had five.

One hundred and eight households $(63.3 \%)$ reported themselves as non-smokers; $65(21.9 \%)$ had one smoker (five cigarettes smoked in the home per day); $42(14.1 \%)$ had two smokers; and two homes had four smokers.

Table I shows the social class distribution of our families compared with the figures for North Staffordshire from the Office of Population Censuses and Surveys. No association was found between social class and any of the clinical variables or the environmental variables, eg, smoking, levels of occupancy of house or

Table I Social class sample $(n=297)$ compared with that for Stoke-on-Trent distribution of the study

\begin{tabular}{|c|c|c|c|}
\hline Class & $\mathrm{n}$ & "o & $\begin{array}{l}\text { OPCS } \\
\text { Stoke-on-Trent } \\
\text { of a } \\
0_{0}\end{array}$ \\
\hline $\begin{array}{l}\text { I } \\
\text { II } \\
\text { III } \\
\text { IV } \\
\text { V }\end{array}$ & $\begin{array}{r}26 \\
83 \\
153 \\
24 \\
11\end{array}$ & $\begin{array}{c}8.7 \\
28 \\
51.5 \\
8.1 \\
3.7\end{array}$ & $\begin{array}{r}3.5 \\
18.5 \\
55.9 \\
15.9 \\
6.2\end{array}$ \\
\hline
\end{tabular}

Table II Comparison of bedroom and living room temperatures and relative humidities for children with and without reported upper respiratory tract infection (URTI), recorded URTI, and recorded acute otitis media (AOM)

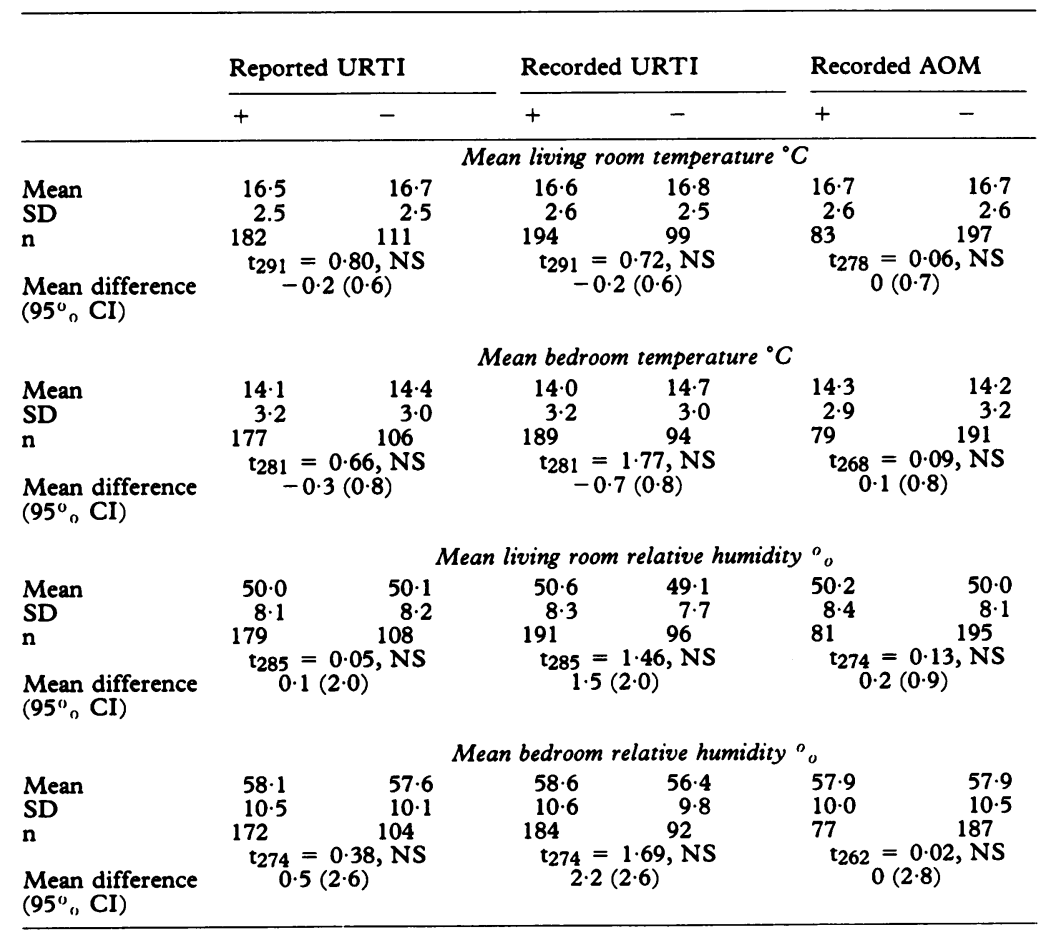

$\overline{C I}=$ confidence interval bedroom, and the presence and forms of house heating.

Repeat visits were made during May and June to 58 houses. Analysis of the duplicate readings using the Kappa statistic revealed that the questionnaire was consistently completed by parents. (The Kappa value may vary from -1 for total disagreement, to +1 for total agreement: a Kappa value of zero indicates chance agreement only.) In the reported incidence of wheezing, smoking, and type of house heating the concordances on the Kappa statistics were 0.48 , 0.78 and 0.6 respectively.

CLINICAL DATA

Three measures of the children's health have been investigated in more detail: (1) attacks of upper respiratory tract infection reported on the questionnaire survey-"reported URTI"; (2) attacks of upper respiratory tract infection recorded in the child's medical records"recorded URTI"; and (3) attacks of actute otitis media recorded in the medical records"recorded AOM". The mean living room and bedroom temperatures and humidities recorded in the houses of the children with and without these conditions are shown in table II. It can be seen that there are no significant differences for any of the variables between any of the groups. The individual indices of health are discussed below.

REPORTED UPPER RESPIRATORY TRACT INFECTION

One hundred and eighty six children $(62 \cdot 6 \%)$ had at least one upper respiratory tract infection in the two week period, of whom $34(11.4 \%)$ were seen by a doctor. Although there are no significant differences in the mean conditions shown in table II, when compared with the $11(34.7 \%)$ children in the group without upper respiratory tract infection, the bedrooms of the children with upper respiratory tract infections tended to be cooler overnight (mean daily adjusted minimum temperature $t_{281}=2.30, p<0.05 ;$ mean difference $=0.8^{\circ} \mathrm{C}, 95 \%$ confidence interval $0.7^{\circ} \mathrm{C}$ ) and consequently to have a higher adjusted maximum relative humidity $\left(t_{274}=2 \cdot 65\right.$, $\mathrm{p}<0.001 ;$ mean difference $=4.6 \%, 95 \%$ CI 3.4$)$. No association was found between the cooler bedrooms and social class.

REPORTED RESPIRATORY SYMPTOMS

No association was found between environmental factors and the reporting of "usual cough", attacks of asthma, or bronchitis. Only 15 children were identified by parents as having had asthma in the previous 12 months, but $58\left(19.5^{\circ}{ }_{0}\right)$ were identified as having had a "wheezy chest" at some time. An analysis comparing these 58 children with the remaining 239 non-wheezers showed that a greater proportion of children who wheezed had gas fires rather than central heating as the main form of heating in the home; children with radiators in their bedrooms were more likely to be non-wheezers; households of wheezing children also tended to have more smokers of at least five cigarettes per day in the home; and wheezers slept in bedrooms with a higher relative humidity which our data showed was due to lower 
Table III Comparison of "wheezers" and "nonpresence/absence of gas fire or central heating or central heating radiator in child's bedroom; by parents' smoking habits, and by relative humidity of bedroom wheezers" by the

\begin{tabular}{|c|c|c|}
\hline & $\begin{array}{l}\text { Non- } \\
\text { wheezers }\end{array}$ & Wheezers \\
\hline $\begin{array}{l}\text { Gas fire } \\
\text { Central heating }(\mathrm{CH}) \\
{\left[\lambda^{2}(1)=7.23, \mathrm{p}<0.01\right]}\end{array}$ & $\begin{array}{r}46 \\
181\end{array}$ & $\begin{array}{l}20 \\
33\end{array}$ \\
\hline $\begin{array}{l}C H \text { radiators in bedroom } \\
\text { No } C H \text { radiators } \\
{\left[\lambda^{2}(1)=4.65, p<0.05\right]}\end{array}$ & $\begin{array}{r}171 \\
68\end{array}$ & $\begin{array}{l}33 \\
25\end{array}$ \\
\hline $\begin{array}{l}\text { Non-smokers } \\
\geqslant 5 \text { cigs } / \text { day }(+) \\
{\left[\lambda^{2}(1)=7.00, p<0.01\right]}\end{array}$ & $\begin{array}{r}160 \\
79\end{array}$ & $\begin{array}{l}28 \\
30\end{array}$ \\
\hline $\begin{array}{l}\text { Adjusted relative humidity } \\
\gtrless 70 \% \\
\text { Adjusted relative humdity } \\
>70 \% \\
{\left[\lambda^{2}(1)=6.80, p<0.01\right]}\end{array}$ & $\begin{array}{r}199 \\
25\end{array}$ & 39 \\
\hline
\end{tabular}

temperatures, not to higher vapour pressures. There was no association between social class and cigarette smoking or any of the respiratory symptoms.

RECORDED UPPER RESPIRATORY TRACT INFECTION

The search found that 198 children $(66.7 \%)$ had received medical attention for an upper respiratory tract infection during the study period. No association was found in this group with domestic temperature/humidity or social factors when compared with the remaining children.

\section{RECORDED ACUTE OTITIS MEDIA}

Table IV shows the distribution of the number of attacks of acute otits media among the children, of whom $127(42.8 \%)$ were identified as having had no attacks of otitis media during their lifetime. On comparing the temperature/humidity and sociodemographic data of this group with the remainder, no important differences were found. Similarly no important differences were found when comparing those children who had had two or more attacks of actute otitis media with the remainder.

\section{Discussion}

In terms of measurement of domestic temperature and humidity, our study was feasible because we were able to record simultaneous measurements of external temperature and humidity. Our sample of 144 hours gave readings (mean, maximum and minimum) which could be corrected to reflect the ambience of that house throughout the study period. The question arises whether the results of a six day recording period can be extrapolated to cover the winter season. It

Table IV Number of acute otitis media (AOM) attacks in the study sample $(n=297)$

$\left.\begin{array}{ll}\begin{array}{l}\text { No of attacks } \\ \text { of AOM }\end{array} & \begin{array}{l}\text { No of } \\ \text { children }\end{array} \\ \hline 0 & 127 \\ 1 & 73 \\ 2 & 37 \\ 3 & 25 \\ 4 & 10 \\ 5 & 7 \\ 6 & 0 \\ 7 & 1 \\ 8 & 3\end{array}\right\} \quad 156\left(55 \cdot 1^{\circ}{ }_{0}\right)$

is the accepted wisdom among building research scientists that this methodology is acceptable, though published evidence is difficult to find. Continuous thermohygrograph recordings from five homes over a four month period in a similar survey in Edinburgh confirm that homes tend to retain their humidity ranking over a wide range of winter weather conditions, and that adjustments of internal measurements for external conditions are valid and reproducible. ${ }^{14}$

Access to private homes has not been easily available to research workers and there is a limited amount of data in this area. It is therefore relevant that we found surprisingly little variation in terms of temperature and humidity between different ages and types of houses (semidetached, terraced, and detached) and between families of different social class within our sample, and the vast majority of homes fell within the normal ranges of temperature and humidity. We cannot claim that the housing sample described here is representative of the country as a whole, and social classes IV and V were moderately underrepresented in our study group. Nevertheless it was surprising that we showed no correlation between smoking and social class.

Obtaining accurate and adequate information on the incidence of upper respiratory infection is difficult. A health diary might have supplied more information, but we decided this was asking too much from a young mother, and it would have presented us with greater problems of accuracy, sustainment, monitoring and funding. Self diagnostic levels of upper respiratory tract infection are notoriously variable in different people, but a two week period was likely to be reasonably accurate in terms of memory recall and our results showed an acceptable degree of reliability in responses.

Our definitions of upper respiratory tract infection were arbitrary, and while we attempted to identify the wheezing child we accept that in practice some children with recurrent upper respiratory infections, especially in the younger age groups, have asthma.

Nearly two thirds of the children were reported as having an upper respiratory infection during the two week recording period, which seems a surprisingly high figure. The bedrooms of these children were cooler than those of the group without upper respiratory infection but this temperature difference was small and only a little greater than the accuracy of the thermohygrograph $\left( \pm 0.5^{\circ} \mathrm{C}\right)$. While the results of our measurements were not uniformly consistent, our findings that a greater proportion of the homes of children who wheezed had gas fires rather than central heating, that nonwheezers tended to have radiators in their bedrooms, and that wheezers slept in the bedrooms that tended to be cooler $\left(t_{180}=1.89, p\right.$ $=0.060$; mean difference $=0.9^{\circ} \mathrm{C}, 95^{\circ}{ }_{0} \mathrm{CI} 1.04$ ) together suggest that cooler bedroom temperatures may be a relevant factor in wheezing in children.

While there is a considerable amount of work published on the health effects and sources of indoor air pollution, 1516 there are surprisingly few publications on the physical qualities of domestic indoor environment and its relationship 
to illness and health. We were unable to show any association between upper respiratory tract infection and domestic temperature/humidity levels of any significant degree in practical terms. In view of repeated assertions in the media that dampness is a health risk, we suggest that further studies in this area are required.

We thank Joan Barrett and Elaine Cooke, our Research Assistants, for their painstaking work; the Department of Physics, University of Keele; the Practice patients and doctors for their help and cooperation; and the Research Advisory Committee of the North Staffordshire Medical Institute for funding this study. Copies of the data set are available from Dr Collins.

1 Morbidity statistics from general practice, 1981-2. (Third National Study, microfiche.) London: Her Majesty's

2 Dingle JH, Badger GF, Feller AE, et al. A study of illness in a group of Cleveland families $A m \mathcal{F} H y g$ 1953; 58: $16-46$ and a group of

3 Green GH. Field studies of the effect of air humidity on respiratory diseases. Indoor climate. Proceedings of the First International Indoor Climate Symposia in Copenhagen August 30th to September 1st, 1978. Danish Building Research Institute Copenhagen, 1979.

4 Van Cauwenberge PB. Epidemiology of common cold. Rhinology 1985; 23: 273-82.
5 Melia RJW, Florey C du V, Morris RW et al. Childhood respiratory Illness and the home environment. II. Association between respiratory illness and nitrogren dioxide, temperature and relative humidity. Int $\mathcal{f}$ Epidemiol 1982; 11: 164-9.

6 Kingdom KH. Relative humidity and air-borne infections. Am Rev Respir Dis 1960; 81: 504-12.

7 Minkle LE, Murray SH. The quality of indoor air. Bull NY Acad Med 1981; 57: 827-43.

8 World Health Organization. Health aspects related to indoor air quality. Report of a WHO Working Group. Euro air quality. Report of a WHO Working Gro

9 Sanders CH, Cornish JP. Dampness: one week's complaints in five local authorities in England and Wales. London: Her Majesty's Stationery Office, 1982.

10 Meteorological Office. Handbook of meteorological instruments. 3, 2nd ed. Meteorological Office, 919c. London: Her Majesty's Stationery Office, 1980.

11 British Standard 1339: 1965. Definition, formulae and constants relating to humidity of the air. London: British Standards Institution, 1965.

12 Hunt DRG, Gidman MI. A national field survey of house temperatures. Building and Environment 1982; 17: 107-24.

13 Kramer MS, Feinstein AR Clinical biostatistics: the biostatistics of concordance. Clin Pharmacol Ther 1981; 29: biostatistics

14 Strachan DP, Sanders C. Damp housing and childhood asthma: respiratory effects of indoor air temperature and relative humidity. $₹$ Epidemiol Community Health 1989; 43: 7-14.

15 Samet JM, Marbury MC, Spengler JD. Health effects and sources of indoor air pollution, Part I. Am Rev Respir Dis 1987; 136: 1486-508.

16 Samet JM, Marbury MC, Spengler JD. Health effects on sources of indoor air pollution, Part II. Am Rev Respir Dis 1988; 137: 221-42. 